\title{
LOS MARCOS DE INTERPRETACIÓN DE LA VIOLENCIA DE GÉNERO EN LAS TELEVISIONES DEL ESTADO ESPAÑOL. MODELOS Y TENDENCIAS
}

\section{Emma Gómez Nicolau}

emma.gomez@uv.es

Universitat de València

Recibido: 27-02-2012

Aceptado: 18-03-2012

\section{Resumen}

En los últimos años la violencia de género se ha convertido en un problema social de primera magnitud, cobrando especial atención los medios de comunicación por su responsabilidad en la construcción de realidades sociales. El objetivo de este artículo es analizar el tratamiento informativo de la violencia de género y su papel en la construcción de marcos de interpretación que dotan de significado el concepto de violencia de género. Para ello, se ha aplicado el análisis crítico del discurso a las noticias de cuatro televisiones del Estado español en la semana alrededor del Día Internacional contra la Violencia de Género de 2010.

Palabras clave: Violencia de género, televisión, cambio social, tratamiento informativo.

\begin{abstract}
Violence against women and its news coverage has become a social and political challenge. The aim of this article is to inquiry about the media responsibility within the gender-based violence social representation. The qualitative inquiry is extremely useful exposing what is not always easy to be seen. The critical analysis has been applied to the TV news. The discourses in four different Spanish media companies have been analyzed during the week around the International Day against Gender-Based Violence, in 2010.
\end{abstract}

Keywords: Gender-based violence, television, social change, news coverage. 


\section{Introducción}

Con esta introducción se pretende, por una parte reiterar la crítica de muchas investigadoras sobre la postura de los medios de comunicación que "parecen haber descubierto la violencia de género" (Vives-Cases, 2005; Varela, 2003; Alberdi y Matas, 2002; Marugán y Vega, 2002) y, al mismo tiempo, redefinir el papel que los medios de comunicación tienen en la imposición de marcos de interpretación. De hecho, sólo cuando la agenda política y la agenda mediática se retroalimentan podemos hablar de cambios en las percepciones sociales.

En este artículo se analizan los discursos informativos de cuatro televisiones del Estado español, dos de ámbito estatal y dos autonómicas — TVE, Antena 3, TV3 y Canal9—alrededor del 25 de Noviembre de 2010, Día Internacional por la eliminación de la Violencia de Género. Los motivos para acercarnos a la semana del 22 al 28 de noviembre de 2010 son varios.

Por una parte, los medios se acercan a la violencia de género con reportajes y especiales. Contenidos con más carga discursiva que las noticias sobre hechos - muertes, detenciones, lesiones y juicios- que permiten un análisis crítico del discurso más rico. Por otra, a partir de 2004, con la irrupción de la Ley 1/2004 de 28 de diciembre de Medidas de protección Integral contra la Violencia de Género, nos encontramos con la consolidación de lo que se puede denominar feminismo de Estado.

Leyes como la 3/2007, de 22 de marzo, para la igualdad efectiva de mujeres y hombres o la creación del Ministerio de Igualdad, a pesar de su corta duración, en abril de 2008, reflejan la asunción, por parte del Estado, de algunas de las demandas del heterogéneo movimiento feminista. Y si bien el objetivo principal del artículo es analizar la producción discursiva que ejercen los medios a través de los informativos de televisión, ésta debe relacionarse con las transformaciones que el Estado propone con la legislación, pero también con sus sugerencias y preocupaciones. Los medios, su responsabilidad y sus funciones, aparecen como principal preocupación política en la lucha contra la violencia de género.

\section{La existencia a partir de la enunciación}

Las palabras, los textos y las imágenes construyen realidades. Determinan, dotan de significado, acotan y excluyen. Con su fuerza preformativa, en términos de Bourdieu (1985), el lenguaje es poder, poder sobre las cosas y sobre las personas. Para Witting el lenguaje es un "orden de materialidad" que está "directamente conectado con el campo político en el que todo cuanto atañe al lenguaje, a la ciencia, y al pensamiento, remite a la persona en cuanto subjetividad, y a su relación con la sociedad" (Witting, 1992:54).

La violencia contra las mujeres era una realidad sin nombre. Ahora, no sólo tiene muchos nombres — de género, machista, patriarcal—y es una realidad conocida por el grueso social, sino que nos encontramos ante una diversidad teórica que dota de contenidos a esos nombres. 
Los marcos de interpretación de la violencia de género en las televisiones del Estado español. Modelos y tendencias

Cómo ya se ha apuntado, el movimiento feminista se ha encargado de situar los marcos de interpretación de la violencia de género en relación con los procesos de socialización diferencial de los sexos y la persistencia de definiciones sociales que representan las relaciones entre los géneros como relaciones de subordinación (de Miguel, 2003: 20). En 1989 el movimiento feminista consiguió la reforma urgente del código penal. Se abandonó la denominación de "delitos contra el honor" por "delitos contra la libertad sexual" y se tipificó la violación y la violencia doméstica en función de su reiteración y no de la gravedad de las lesiones producidas. Los éxitos de los movimientos sociales, en este caso el feminismo, pasan por dotar de significados propios los conceptos estratégicos que, siguendo a Witting, tienen esa conexión con el campo político.

El peso de los medios en la configuración de un universo compartido de significados sobre qué es la violencia contra las mujeres se confirma en los resultados de las encuestas encargadas por el Ministerio de Sanidad, Política Social e Igualdad sobre percepción social de la violencia de género. En la edición de 2011, un 74,8\% afirmaba que su conocimiento sobre violencia de género procedía en primer lugar de la TV, un 3,1\% de la radio y un 9,9\% de la prensa escrita. Así pues, un $87,8 \%$ se acerca a esta realidad mediante los medios de comunicación (Ministerio de Sanidad, Política Social e Igualdad, 2011). La importancia de cómo los medios de comunicación se acercan a la violencia de género y cómo trasladan esta realidad a la sociedad se ha visto plasmada en numerosas investigaciones que, desde finales de la década de los 90, se han realizado en el Estado español (Carballido, 2009; Ariznabarreta, 2006; Vives, 2005; Fernández, 2003; Fagoaga, 1999). Se discute la permeabilidad de los medios, su función social y, sobre todo, su responsabilidad ${ }^{1}$ en la permanencia - como agentes de la reproducción del orden patriarcal, al igual que la Iglesia, el Estado o la Escuela (Bouerdieu, 2000) - y/o erradicación de la violencia contra las mujeres. Los estudios se han centrado en la prensa escrita, aunque destacan algunos sobre la televisión como el informe del Consell Audiovisual de Catalunya (CAC, 2008) y los estudios dirigidos por Pilar López del Instituto de la Mujer y el Instituto Oficial de Radio y Televisión (IORTV, 2006; López, 2007). Dada la permeabilidad social de la televisión y su importancia a la hora de dar a conocer la violencia de género se ha considerado oportuno profundizar en el análisis de los discursos que los servicios informativos televisivos elaboran y trasladan a la sociedad.

El grueso de las investigaciones apunta hacia una mejora notable en el tratamiento informativo de la violencia tanto cuantitativa como cualitativamente. Las crónicas de sucesos de El Caso (1952-1987) en que las narración de los "parricidios" se usaba para legitimar la violencia contra las mujeres ${ }^{2}$ se tradujeron en la prensa generalista de la transición en noticias

\footnotetext{
${ }^{1}$ Muestra de la preocupación creciente, cabe destacar la investigación que el ministerio de Igualdad encargó a la Universidad de Granada para analizar la correlación existente entre la aparición en los medios de un caso de agresión y la probabilidad de que suceda otro hecho violento en los días siguientes. ${ }^{2}$ En El Caso se utilizaban tres estrategias principales de legitimación de la violencia: la deshumanización del agresor, la exculpación del agresor mediante factores externos como el alcoholismo, las enfermedades mentales, los celos, etc., o la justificación de la agresión causada por la desviación de la mujer víctima de las funciones prescritas de madre y esposa.
} 
de sucesos que respondían al cliché de crimen pasional (Alberdi y Matas, 2002: 248). Y aunque a partir de los ochenta se empiezan a asociar los crímenes y las agresiones con los maltratos, no es hasta los años noventa y, sobre todo, a raíz del caso Ana Orantes (Granada, 1997), cuando nos encontramos con un tratamiento tematizado que ofrece una visión más profunda del problema y desde una perspectiva más generalizadora, al mismo tiempo que se diversifican los géneros informativos (Carbadillo, 2007). La última etapa estaría caracterizada por la reflexión y control internos de la información y la generalización de un enfoque proactivo por parte de los medios ${ }^{3}$. La violencia de género tiene su espacio en cada medio, se presenta tematizada, reduciendo así la complejidad social para una opinión pública que se halla estrechamente vinculada al sistema político bajo la acción de los media (Xambó, 2010:325).

Ahora bien, que la violencia de género se haya convertido en un problema de Estado, que los medios se ocupen de manera creciente en dar cuenta de ello no significa, sin embargo, que el concepto esté claro. El paso de la denominación violencia doméstica —antes parricidio - a violencia de género ha sido considerado un éxito por el feminismo al recoger sus marcos de análisis: entendida como aquella violencia que sufren las mujeres por el hecho de ser mujeres, asentada sobre el sistema sexo/género y orquestada por el orden patriarcal (Osborne, 2009; Alberdi, 2005, 2002; Varela, 2003, 2002; Bosch y Ferrer, 2002; Lorente, 2001).

La violencia de género incluye, según la Naciones Unidas (ONU, 1993) además de la violencia física, sexual y psicológica que se produce en la familia (malos tratos, abuso sexual de niñas en el hogar, violencia relacionada con la dote, violación marital, mutilación genital femenina y la violencia relacionada con la explotación), la violencia física, sexual y psicológica perpetrada dentro de la comunidad en general (violación, abuso sexual, acoso, intimidación sexual en el trabajo, en las instituciones educativas, la trata de mujeres y la prostitución forzada) y también la violencia física sexual y psicológica perpetrada o tolerada por el Estado.

Para la Ley Integral de Medidas de protección contra la Violencia de Género (en adelante, LIGV), sin embargo, la violencia de género es aquella que "como manifestación de la discriminación, la situación de desigualdad y las relaciones de poder de los hombres sobre las mujeres, se ejerce sobre éstas por parte de quienes sean o hayan sido sus cónyuges o de quienes estén o hayan estado ligados a ellas por relaciones similares de afectividad, aun sin convivencia" (Título Preliminar, Artículo 1: 42168). La LIVG, a pesar de ser de las pocas leyes europeas que tratan la violencia desde un enfoque de igualdad de género (Bustelo, López y Platero, 2007:74), circunscribe la violencia de género a la violencia contra las mujeres en la pareja (Bosch, Ferrer y Alzamora, 2006:97). Y cuando nos acercamos a los discursos mediáticos sobre la violencia nos encontramos con el zoom puesto en la violencia que se ejerce contra las mujeres por parte de parejas o ex parejas en relaciones heterosexuales (García y

\footnotetext{
${ }^{3}$ Un buen indicador de la implicación de los profesionales en la autocrítica es la proliferación de manuales de estilo, recomendaciones y guías para un buen tratamiento de la violencia de género (Alsius, 2009).
} 
Casado, 2010). Ésta es la violencia que se ha convertido en un problema social de primera magnitud y sobre la que los medios de comunicación han puesto el foco de atención. El zoom está más que legitimado por la crudeza de las cifras. El año 2011 se cerró con 61 víctimas mortales y el teléfono de atención a las víctimas (016) recibe una media de 180 llamadas telefónicas diarias desde septiembre de 2007 (Observatorio de la Violencia, 2010). A pesar de la importancia de estas cifras, confundir violencia de género con violencia en la pareja dificulta la comprensión compleja del problema social a la vez que oculta las diferencias en las maneras de abordarlo.

De hecho, en el ámbito teórico están surgiendo voces disidentes ante lo que se denomina un marco hegemónico de representación de la violencia de género. Siguiendo a Ana León, "el patriarcado aparece en los escritos feministas como ese mecanismo causal que explica todas las desigualdades de género. Sin embargo, la ausencia de una definición analítica de este concepto hace que se haya convertido en la causa y consecuencia de todo comportamiento discriminatorio" (León, 2009:561). En la misma línea, Fernando García y Elena Casado sostienen la necesidad de distinguir entre violencia y conflicto, al tiempo que reivindican el estudio de la violencia en las relaciones de género y de pareja de manera relacional, en el marco de las transformaciones sociales que han afectado, de manera decisiva, a los modelos familiares (García y Casado, 2010:235-263).

\section{El análisis crítico del discurso. Modelos y tendencias discursivas en televisión sobre violencia contra las mujeres}

Para analizar los discursos de los medios sobre violencia de género se ha recurrido al Análisis Crítico del Discurso (ACD). Lejos de ser una técnica precisa de análisis sociológico, se trata de una denominación genérica que se aplica a estudiar los textos que emerge de la crítica linguiística, la crítica semiótica y el modelo sociopolítico consciente y oposicionista en el que se investiga el lenguaje, el discurso y la comunicación (Van Dijk, 1997). El ACD se utiliza para descubrir y divulgar lo que está implícito o lo que no es inmediatamente obvio en las relaciones de dominación discursiva. Se trata de poner de manifiesto las relaciones entre el discurso y las diferentes representaciones colectivas que luchan por imponerse en los medios entendidos como campo (Bourdieu, 1997). Porque en esa lucha se impondrán las representaciones dominantes que, en definitiva, tienen un impacto en la negociación de las actitudes, creencias, experiencias e identidades (Kitzinger, 1999). Para Fernando Conde, el análisis sociológico del sistema de discursos defiende la existencia de una fuerza y de un poder propio de los discursos, que le vendría dado también por su fuerza simbólica intrínseca y por su capacidad de conexión y de canalización de las tensiones y de las luchas sociales que hacen de los conflictos discursivos un componente esencial de las luchas políticas, ideológicas y sociales (Conde, 2009).

La muestra la componen los informativos de la noche de cuatro televisiones - dos de ámbito estatal, TVE y Antena 3; y dos autonómicas, TV3 y Canal9- del 22 al 28 de 
noviembre de 2010, contexto de la celebración del Día Internacional contra la Violencia de Género el 25 de noviembre. Nos encontramos con un grueso de noticias que responden a unas rutinas periodísticas especiales ${ }^{4}$. No obstante, en la muestra también aparecen las noticias cotidianas relacionadas con el tema.

La selección de las emisoras se ha seguido atendiendo a criterios de diversidad en su sistematización del tratamiento informativo. Con estudios sobre el tratamiento informativo de la violencia de género (IORTV, 2006) y un manual de estilo específico, la dirección de RTVE ha mostrado la preocupación por revisar el discurso mediático respecto a la violencia contra las mujeres. El punto de inflexión, no obstante, lo promovió la aprobación de la LIVG, que incorporaba consideraciones sobre la responsabilidad de los medios de comunicación desde el título preliminar ${ }^{5}$. Antena 3, por su parte, con menores recursos que la televisión estatal, ha mostrado su implicación. En 2010 realizó la segunda campaña contra la violencia de género ${ }^{6}$.

En Cataluña existe desde 2000 el Consell Audiovisual de Cataluña (CAC), organismo público independiente regulador del audiovisual. En este contexto, la TV3 tiene a su servicio los análisis que el CAC ha venido haciendo sobre el tratamiento de la violencia contra las mujeres en los informativos y se encuentra sujeta a las recomendaciones que el organismo elabora ${ }^{7}$. Por su parte, Canal9, la televisión pública valenciana, carece tanto de marco legal autonómico propio, como de análisis relativos al tratamiento informativo sobre la violencia de género.

\subsection{Del zoom a la apertura de plano}

En el aspecto cuantitativo, las 30 noticias que componen la muestra sobre violencias que se ejercen contra las mujeres se distribuyen de la siguiente manera. En TVE se contabilizan 11

\footnotetext{
${ }^{4}$ Entendemos como rutinas especiales la flexibilización de las mismas: no estar sujetos a las imágenes de agencia por la posibilidad de preparar materiales propios con antelación, tener la certeza de su inserción en la escaleta, no estar constreñidos por los límites de espacio ni por los criterios de noticiabilidad, etc.

${ }^{5}$ En el título preliminar, la ley se marca como objetivo "fortalecer las medidas de sensibilización ciudadana de prevención, dotando a los poderes públicos de instrumentos eficaces en el ámbito educativo, servicios sociales, sanitario, publicitario y mediático" (Art. 2, Título Preliminar). De esta manera, los medios se explicitan como una herramienta imprescindible en la tarea de resocializar a la ciudadanía en términos de igualdad. Y en el artículo 14 del Capítulo II dice que "los medios de comunicación fomentaran la protección y salvaguarda de la igualdad entre hombre y mujer, evitando toda discriminación entre ellos. La difusión de informaciones relativas a la violencia sobre la mujer garantizará, con la correspondiente objetividad informativa, la defensa de los derechos humanos, la libertad y la dignidad de las mujeres víctimas de violencia y de sus hijos. En particular, se tendrá especial cuidado en el tratamiento gráfico de las informaciones".

${ }^{6}$ Se puede ver la campaña en http://www.antena3.com/especiales/noticias/sociedad/antena-3-noticiascontra-la-violencia-de-genero/campana-antena-noticias-violencia-genero_2010111000109.html

${ }^{7}$ En 2009 el CAC puso a disposición de los profesionales las recomendaciones actualizadas a raíz de la promulgación de una nueva ley autonómica, la 5/2008 del Parlament de Catalunya, que obliga a dar a conocer las noticias sobre hechos relacionados con la violencia machista, excluyendo los elementos que puedan darle una carácter morboso (Art. 23, Cap II).
} 
piezas informativas; 9 en Antena 3; 5 en TV3 y 8 en Canal9. El tiempo dedicado a hablar sobre la violencia de género en sus diversas facetas es muy diferente según la cadena.

Centrándonos en el contenido de las piezas informativas, encontramos el primer aspecto relevante para el análisis cualitativo: qué tipo de violencia se plasma en la televisión. Nos encontramos con el zoom puesto en la violencia que se ejerce contra las mujeres con las que se tiene o se ha tenido un vínculo, una relación sentimental. En el gráfico se han segregado las informaciones según el aspecto de la violencia de género que se representa:

Gráfico 1: Aspecto de la Violencia de género representada en las piezas informativas y tiempo dedicado (22-28 noviembre 2010. Informativos de la noche.)

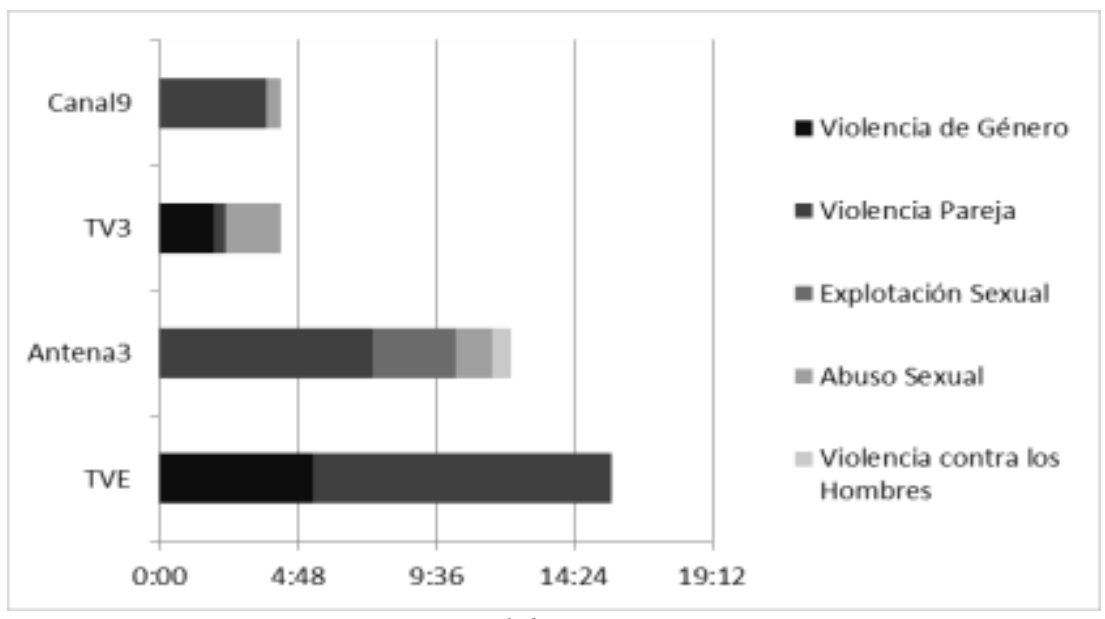

Fuente: Elaboración propia

Con el descriptor Violencia de Pareja se han identificado las noticias que se centran exclusivamente en la violencia que se ejerce contra las mujeres con las que se tiene o se ha tenido un vínculo. Se incluyen no sólo las muertes y/o agresiones de una mujer a manos de su ex marido, con un tratamiento informativo reducido a sucesos, breves y con escasa contextualización sino que, la jornada del 25 de noviembre de 2010 estuvo marcada por el anuncio del gobierno de la reforma del Código Civil para que los hombres imputados perdiesen la custodia individual de sus hijos. Todas las informaciones al respecto, pues, se centraban en la violencia en las parejas con hijos. También lo hacían las piezas en el recuerdo a las mujeres víctimas a manos de sus parejas o ex parejas y los balances sobre la aplicación de la LIVG.

Las informaciones sobre trata o prostitución entendida como forzada se enmarcan en el código Explotación Sexual ${ }^{8}$ Y bajo Agresión Sexual agrupamos las piezas centradas en dar a conocer casos, juicios o resultados de juicios de hombres que han cometido violaciones.

\footnotetext{
${ }^{8}$ El concepto explotación sexual parece exento de complejidad y, sin embargo, encierra una de las más apasionantes discusiones dentro del feminismo entre partidarias de la legalización de la prostitución como
} 
Por último, bajo el epígrafe Violencia contra los Hombres, citamos la única información de la muestra que se centra en el resultado de culpabilidad a una mujer por "matar a su marido con una pesa de gimnasio" (A3, 26/11/2010).

A través de esta radiografía podemos observar como los discursos sobre violencia de género están atravesados por el sesgo que supone ejercer ese zoom sobre la violencia física con consecuencias mortales. Los medios, no obstante, comparten este sesgo con la LIVG, siendo un buen ejemplo de la retroalimentación de la agenda mediática a través de la agenda política.

\subsection{Del suceso aislado a la complejidad del contexto}

En la muestra de todas las televisiones, aparecen noticias que se ajustan al breve de sucesos, en ningún caso ocupan un minuto. La reducción al mínimo es la norma y se siguen los principios básicos que recogen las recomendaciones: no hay detalles sobre los modos de actuación, se respeta la presunción de inocencia, no hay adjetivación ni consideraciones morales sobre los hechos o los actores, etc. Cuando se trata de breves sobre juicios, la estrategia es la misma. Aunque los breves no contengan elementos que se puedan catalogar como un mal tratamiento, tampoco aportan información útil a la ciudadanía.

En el polo opuesto nos encontramos las informaciones especiales; con testimonios, con mensaje social y con carga emotiva. Desglosando los especiales por cadenas, TVE, con más de 8 minutos, construye un discurso edificante cuyo objetivo es mostrar una realidad compleja. El especial empieza con el anuncio del gobierno sobre la reforma legal para retirar la custodia individual de los hijos y aporta las dos posiciones al respecto, la del gobierno y las críticas de las asociaciones de jueces que la consideran "innecesaria y propagandística". De esta presentación en plató se da paso al primer video sobre los problemas de los juicios rápidos que impiden investigar si una denuncia tiene o no fundamento. Para evitarlo, se traslada la petición del Observatorio contra la Violencia de implantar más unidades de evaluación forense. El recuerdo de Ana Orantes y el testimonio de lucha recogido por su hija centran la segunda parte del especial, destacan la importancia del caso para cambiar la percepción social de la violencia contra las mujeres y que supuso la implicación de los medios. Acaban con tres conexiones en directo con los corresponsales en Alemania, Italia y EEUU, que explican cómo se aborda la problemática en estos países. En suma, un discurso edificante porque abarca reformas legales en marcha, puntos débiles de la implantación de la LIGV, reconstruye las transformaciones de la percepción social y sitúa el problema en el marco internacional.

Antena 3 también empieza desde plató con la estricta actualidad, la reforma de la ley y pasa directamente a comentar que "en lo que va de año, 64 mujeres han muerto asesinadas en nuestro país a manos de sus parejas", que "ya son más que en todo 2009". La pieza siguiente se traslada a la conmemoración en la Gran Vía con el "paseo de la vergüenza", donde se exhiben en forma de estrella casos de maltrato. Un zoom muestra la inscripción en una estrella:

actividad privada y libre y la postura abolicionista, que entiende que la prostitución implica siempre violencia y un abuso de poder por parte de los hombres. 
"Mercedes M. 58 años. España. Quemada viva por su marido". La tensión y la espectacularidad se reflejan en frases como "Unas muertas y otras supervivientes". La pieza se complementa con el testimonio de una mujer que explica su experiencia: "me echó una cuerda por el cuello. Lo que pasa es que con la mano yo conseguí agarrar la cuerda y gracias a ello conseguí, y no pudo ahorcar, ahogar o lo que él pretendiera". Y prosigue "Retiró una denuncia. Una situación que en los últimos años se ha incrementado un 46\%. Cuando la mujer está ante el juez se acoge a su derecho a no declarar. Quienes han salido dicen que callar es un error para ellas y para sus hijos". La selección de citas destila una persistente dramatización e impacto emocional. El uso de los testimonios en primera persona suele valorarse muy positivamente en la cultura periodística sin reflexionar si aporta o no algo interesante. Para acabar la pieza, se pide la denuncia como método contra la violencia, un discurso que dirige la responsabilidad hacia las mujeres que no denuncian: "se sigue pidiendo en todos los idiomas que denuncien, que nadie mire a otro lado". Este es uno de los nuevos mitos elaborados y difundidos: la presión a la denuncia responsabiliza a las mujeres de su situación. Cabe comentar la centralidad que tiene el recuento de víctimas mortales.

El especial de TV3 se reduce a dos piezas de apenas 30 segundos cada una. En la primera se informa de los actos de la plaza Sant Jaume y las reclamaciones de los manifestantes para "visibilizar a las mujeres que sufren en silencio episodios de violencia". A continuación, el anuncio de reforma legal. Aquí se indica que "En Catalunya, estas medidas ya existían. Des de 2008 a los maltratadores se les prohíbe heredar". Noticias cotidianas, sin más preparación de lo habitual, sin adornos. La postura de TV3 la entendemos, sin embargo, a través de la primera unidad de análisis de la muestra. El lunes de la misma semana, la noticia era la siguiente: "El gobierno español plantea pactar con los medios de comunicación cómo tratar la información sobre la violencia de género para evitar un posible efecto llamada sin descartar la opción de dejar de informar sobre un tiempo" (TV3, 22/11/2010). En la pieza de 1:30 minutos se entrevista a Miguel Lorente Acosta, delegado del gobierno en materia de violencia de género, analizando las claves de lo planteado, las evidencias empíricas con las que se está trabajando sobre la influencia social de los medios: comportamientos vicarios, aprendizaje de maneras de llevar a cabo crímenes, identificación de los agresores con situaciones de dolor expuestas, etc. Esta noticia supondrá un punto de inflexión en el tratamiento que TV3 hará de la violencia de género, intentando que la misma pase desapercibida.

En último lugar, Canal9 elabora un discurso muy parecido al de A3. Su primera pieza es de homenaje a las víctimas mortales. Imágenes de una manifestación con numerosas opiniones de la calle. Empieza: "En recuerdo de las mujeres asesinadas por la violencia machista... hoy todo es poco para recordar a las mujeres muertas a manos de los que algún día dijeron que las querían. Nosotros, con ésta tirita, mostramos la solidaridad con las víctimas y enviamos un

\footnotetext{
${ }^{9}$ Se ofrece directamente la traducción al castellano de las citas de TV3 y Canal9, originales en catalán, por las constricciones de espacio.
} 
mensaje a quien sufre la violencia dentro de casa: denunciar la agresión”. Dramatismo y solemnidad, y de nuevo la solución pasa por la denuncia de las víctimas. Cabe destacar la referencia a "dentro de casa", restringiendo la significación de la violencia de género a la "doméstica". A este planteamiento inicial se le suman comentarios y opiniones que carecen de información relevante o novedosa, por parte de mujeres que quedan sin identificar. La pieza acaba con el testimonio directo de una mujer que vivió violencia y con el testimonio de unos padres cuya hija murió y su empeño por cambiar la ley para que los procesados cumplan la pena íntegra. La interpretación de esta pieza destaca el sensacionalismo en expresiones como "Para otras es demasiado tarde" y el uso de una noticia de sensibilización como escaparate de ideologías políticas. La última pieza se centra en la iniciativa gubernamental de reforma del Código Civil para retirar la custodia a los maltratadores. En menos de 30 segundos, introducen las críticas de los jueces diciendo que "la consideran propagandística y la califican de peligrosa y de absurda". Calificaciones que se lanzan sin haber explicado el contenido de la propuesta son algo más que el traslado de la opinión del colectivo de jueces.

Nos encontramos, así pues, con la convivencia de dos modelos dentro de cada uno de los medios: la permanencia de las noticias breves, descontextualizadas y sin información que coexisten con los reportajes, grupos de noticias entrelazadas que aportan explicaciones más profundas y ricas. Ahora bien, la profundidad requiere de un mayor posicionamiento político y de mayor formación. Como hemos visto, las piezas más largas que incluyen testimonios son las que en algunos casos introducen distorsiones en la coherencia de los discursos y permiten la entrada de tópicos y mitos sobre la violencia.

\subsection{De la mujer víctima a las mujeres como colectivo de transformación social}

En pocas ocasiones las mujeres son tan protagonistas de la información como en la dedicada a la violencia (Gallego, 2002), de manera que en las unidades de análisis utilizadas para la investigación nos encontramos con muchas mujeres que, como consecuencia del ejercicio de la violencia contra ellas, se convierten en protagonistas. En las noticias de sucesos aparecen como víctimas, generando así la imagen de mujer sujetada, dependiente, indefensa e incapaz de tomar las riendas de su vida. Una imagen que no beneficia en absoluto el romper con las identidades de género dominantes, ancladas en la diferenciación sexual.

TVE opta por dar el paso y privilegiar la voz de algunas mujeres que, en plural, se erigen como sujeto transformador de la realidad social. Es el caso de Suraya Pakzad de quien dice que es una "activista afgana [...] vive en Herat, amenazada de muerte, separada de su familia y no piensa marcharse"; "su organización tiene refugios para mujeres maltratadas y mira también al futuro con escuelas para mujeres líderes" (TVE, 23/11/2010). Pakzad representa el contramodelo. Raquel Orantes, la hija de Ana Orantes, aparece como una mujer luchadora a pesar de las circunstancias: "ella transformó el dolor y la rabia en lucha contra esta lacra" (TVE, 25/11/2010). Aporta conocimientos, no sólo personales sino sobre las 
transformaciones sociales en materia legal. No es una experta, sí una mujer empoderada. Otra mujer en proceso de estar empoderada, en la misma noticia, explica los fallos del sistema a partir de su experiencia personal: "Si me he demorado el tiempo que me he demorado en denunciar es precisamente porque tengo miedo de que no me crean. Y tengo miedo de provocarlo a él con una denuncia y que vaya a tomar represalias conmigo. Si a mí no me protegen...". Estaría a camino entre el modelo víctima y el de mujer empoderada. Las otras mujeres, las expertas, políticas y profesionales que pueblan las noticias, también las jóvenes, actuarían como modelo normativo. Su presencia normalizada, ejerciendo roles que tradicionalmente ocupaban los hombres, es el actual modelo prescrito por los medios de comunicación.

En Antena 3, por el contrario, abunda el modelo de mujer víctima y faltan contramodelos. En los reportajes sobre la prostitución se utilizan los testimonios directos para dar cuenta de la situación de indefensión de las mujeres sometidas a la prostitución forzosa: "Nos pudieron vender, como si fuésemos perros, nos podían matar, si que te podía matar. O revender o matar y llevar a un club de donde no salíamos vivas. Ahora también me temo por mi vida.", la locución sigue: "la trajeron a España con una falsa oferta de trabajo, una vez aquí la llevaron directamente a este prostíbulo de la Jonquera donde trabajaban 12 horas al día y eran vigiladas en todo momento" (A3, 22/11/2010). También como víctimas se representa a las 13 jóvenes que sufrieron abusos: "Se hizo pasar por mentalista, curandero y adivino. Y según el fiscal se sirvió de sus supuestas dotes para engañar a 13 menores y abusar de ellas" (A3, 22/11/2010). Mujeres representadas como víctimas, ingenuas e indefensas. También aparece el modelo institucional encarnado en políticas, psicólogas, abogadas... Y un nuevo modelo que sólo aparece en ésta cadena, el de la mujer agresora: "dio muerte a su marido durante una discusión en su domicilio. [...] condenarla por homicidio con el agravante de alevosía. Aun así, en el veredicto solicita el indulto parcial por considerar que su actuación se debió a toda una vida de malos tratos" (A3, 26/11/2010). Esta información sólo recoge esta cadena, ajena a la influencia que puede tener en la deslegitimación de la LIGV.

En las pocas unidades de análisis de TV3 nos encontramos el modelo institucional y, en la pieza informativa que versa sobre las violaciones de mujeres como técnica de guerra, éstas se representan de la siguiente manera: "las mujeres son el puntal de la comunidad en tiempo de guerra, vigilan el pueblo cuando los maridos están en el frente, trabajan la tierra y mantienen la cohesión social. El tribunal de la Haya lanza un aviso claro: los delitos sexuales sistemáticos no quedarán impunes." (TV3, 22/11/2010) Las mujeres no son víctimas si no hay una vulneración de sus derechos y, de hecho, son la pieza clave de la comunidad. Una interpretación que las aleja de representaciones victimizadas y cabria situarla en el cuadrante del contramodelo.

Canal9 mantiene únicamente representaciones del modelo institucional - mujeres manifestantes y políticas-, y de la víctima: "No me dejaba tener amistades, he perdido contacto con todo, me hacía sentir, pues, dependiente de él. A empujones me levantaba la mano. Y cada vez las agresiones eran más fuertes, hasta he llegado a estar hospitalizada. 
Cuando nació mi hijo, pues digo, a lo mejor cambia, pero me pegaba igual. Todo esto lo observaba mi hijo y hacía igual. Vi que, pues, mi hijo, el día de mañana, será igual un maltratador" (C9, 25/1172010). Al dramatismo que imprime la cita se le suma la introducción de otro de los mitos sobre la violencia de género: que se aprende y se reproduce eliminando toda agencia por parte de las subjetividades.

\section{Cuadro 1: Modelos de mujer representados en los medios de comunicación}

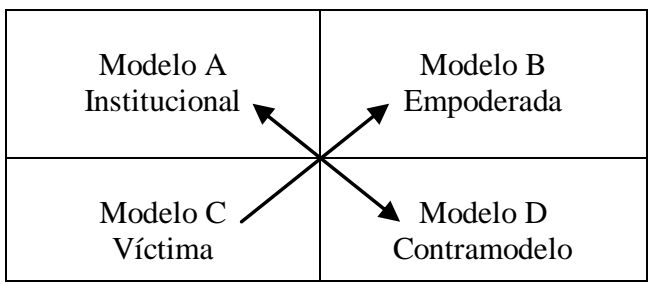

Fuente: elaboración propia

La plasmación gráfica en el cuadro 1 de los modelos representados de mujer sobre el cuadrado M de la modernidad de Alfonso Ortí permite observar cómo a la izquierda del cuadro se quedan las dos opciones más conservadoras mientras que a la derecha quedan las más transformadoras. Así también, se pueden ver los tránsitos permitidos de cuadrante a cuadrante: del A se puede pasar al D y viceversa y del C se puede pasar al B, ahora sí, sin posibilidad de retorno.

\subsection{De maltratador a agente por el cambio}

Por lo que respecta a las representaciones de los hombres, éstas ocurren de manera idéntica. La perpetuación de la representación de los hombres como maltratadores contribuye a su esencialización, a que encarnen la figura del enemigo a batir ${ }^{10}$. La imposición de identidades de género cerradas. En la muestra analizada las categorías más conservadoras se combinan con otras identidades masculinas que promueven el cambio social.

En las noticias de TVE aparecen representados los hombres que luchan por la igualdad desde ámbitos más o menos formales. A través del reportaje Hombres contra el machismo se da voz a los hombres que dirigen terapias de rehabilitación de maltratadores: un catedrático, un psicólogo, sexólogos y sociólogo, y miembros de asociaciones. Explicaciones sobre la viabilidad del tratamiento, límites en la construcción de identidades no violentas, etc. El modelo institucional estaría completado por otros expertos, como los del ámbito político, que

\footnotetext{
${ }^{10}$ Sobre la visión de la categoría de agresor o maltratador como estable hay varios textos críticos que incluso ponen en duda la eficacia de campañas publicitarias como la de "Sácale tarjeta roja al maltratador". Los términos agresor y víctima son siempre relacionales y dependen del contexto. Así pues, nadie es un maltratador siempre ni nadie es víctima a perpetuidad (García y Casado, 2010; León, 2009).
} 
también se recogen en TVE. La figura del maltratador se representa en su proceso de rehabilitación, por tanto, desde el prisma de las identidades abiertas, aunque a través de su cita, éste minimiza su violencia y la justifica por el contexto: "Han habido pues alguna vez empujones, pero bueno en casos así también muy extremos.... No sabría muy bien decirte por qué o por qué razón bueno, siempre lo mismo... llegas pues muy tarde de trabajar, llegas bueno, pues todos los niños..." (TVE, 24/11/2010).

Antena 3 también elabora su especial sobre terapias para maltratadores (A3, 25/11/2010) donde se representan diversos hombres que siguen la terapia: "dos hombres cumplen condena en un centro penitenciario. Maltrataron a sus compañeras y acabaron entre rejas. Es lo que estuvo a punto de ocurrirle a José. Agredió a su ex mujer pero el juez le conmutó la pena a cambio que asistiera a sesiones de terapia en este centro". Dos tipos de maltrato, uno grave - marcado por la pena de prisión - y uno de baja intensidad. El conflicto discursivo aparece, como en el caso de TVE entre la representación como maltratador leve por parte de la noticia, y su autorepresentación minimizante de la violencia: "La agarré de las manos y tuvo unas marcas y fue por eso la denuncia. Y le di una bofetada".

Por otra parte, Antena 3 representa otro tipo de agresores mimetizados con la figura criminal: el explotador sexual. Categoría que no es exclusiva de hombres: "un guardia civil, su mujer y el portero de un macro prostíbulo acusados de explotar sexualmente a tres jóvenes ucranianas. Según el fiscal, las amenazaban y golpeaban si no cumplían sus órdenes" (A3, 22/112010). Sobre el Brujo, acusado de 19 delitos sexuales, se incide en que es un estafador que a través del engaño logra abusar sexualmente de las menores. Esta noticia merece un punto y aparte por la elaboración de la misma. En la pieza informativa se inserta un video de la misma cadena, de un programa sensacionalista de debate donde el Brujo está participando. En el corte de video insertado en la noticia se escucha "Por Dios, que hagan algo con éste hombre, que entren los guardias de seguridad al plató y que se lo lleven...” y, a continuación se explica: "Los espectadores de A3 televisión lo tenían claro. Tomás Arroyo, alias el Brujo, de brujo no tenía nada. Ni de brujo, vidente, mentalista o sanador, por mucho que asegurara en los platós que era capaz hasta de curar el cáncer" (A3, 22/11/2010). Reconstruyen el carácter abyecto del procesado pero, sin embargo, no reflexionan ni se avergüenzan del hecho de contar en sus programas de entretenimiento con colaboradores de ese calibre.

TV3 evita, siguiendo su línea de minimización, representar a hombres. Hay presencia de modelos institucionales y un caso de representación de un malo sin posibilidad de escapar de su identidad. Ahora bien, es una identidad alejada de las de género: se trata del jefe rebelde de la República Democrática del Congo, acusado de crímenes de guerra y crímenes contra la humanidad. Entre estos, la noticia es que La Haya persigue la violación masiva de mujeres como técnica de guerra.

Canal9, para acabar, representa a hombres situados en el modelo institucional: deportistas y políticos. 
Cuadro 2: Modelos de hombre representados en los medios de comunicación

\begin{tabular}{|c|c|c|}
\hline $\begin{array}{c}\text { Modelo A } \\
\text { Institucional }\end{array}$ & $\begin{array}{c}\text { Modelo B } \\
\text { Indeterminado }\end{array}$ & $\begin{array}{c}\text { Modelo C } \\
\text { Agresor/Agresor en } \\
\text { tratamiento }\end{array}$ \\
\hline
\end{tabular}

Fuente: elaboración propia

Ante dos modelos mayoritarios de representación de hombres, institucionales y agresores, y la inexistencia de modelos alternativos o contramodelos, nos encontramos ante la incógnita del modelo resultante de la transformación de los agresores rehabilitados. El modelo B, aunque no está representado, se intuye: ha de haber algo más, algo intermedio. No obstante, ese modelo indeterminado no sería nunca un contramodelo.

\subsection{Del uso instrumental al uso final}

Entrando de pleno en el campo de la manipulación informativa, repasamos las principales estrategias usadas en la muestra que convierten el fin informativo en un medio para ensalzar o dar cabida a posiciones políticas e ideológicas no legítimas.

En TVE nos encontramos con un exceso de representación del gobierno en las informaciones sobre actos institucionales cuya sobredimensión deja fuera a otros agentes, como ahora los contramodelos. Si bien es cierto que la actividad gubernamental en materia de sensibilización debe aprovecharse y trasladarse a la sociedad, no debe ser una excusa para no incluir a movimientos sociales de gran calado social. De hecho, lo hacen cuando centran la mirada en los hombres contra el machismo, pero lo olvidan cuando se trata del movimiento feminista.

Antena 3 hace un uso más pernicioso de su poder para imponer discursos y lo ejemplifica en la noticia que narra la aprobación de la reforma del Código Civil. Con elaboraciones textuales como "la iniciativa del gobierno pretendía obligar al juez a retirar la custodia", "Rubalcaba ha intentado deshacer el entuerto provocado por Leire Pajín" (A3, 26/11/2010), se realiza una interpretación cerrada, sin dejar nada a los espectadores. En la vuelta al plató, además, se dan a conocer los resultados del apoyo popular sondeado a través de una pregunta web. El texto, desde plató, continua: "La mayoría de los internautas, un $68 \%$, no lo apoyan. La actual Ley Integral contra la Violencia de Género ya permite retirar la custodia y la patria potestad como medida cautelar, de hecho ya se ha aplicado en 11.000 casos. En los últimos 5 años se ha suspendido la guardia y custodia del padre en el $8 \%$ de los procesos judiciales por maltrato. Hay otro dato significativo, el $31 \%$ de los 200.000 imputados por Violencia de Género ha sido finalmente absuelto". A la dudosa validez de la recogida de opiniones mediante la pregunta web - que para un espectador poco iniciado en Ciencias Sociales puede tener la misma validez que una encuesta-, se le suma el comentario final sobre la absolución de miles de imputados, que deja entrever el fantasma de las denuncias falsas. 
En TV3, con su mínima muestra, no se da lugar a ningún tipo de uso de noticias sobre violencia con fines instrumentales. Canal9, por su parte, utiliza algunas noticias como mostrador de ideologías. Lo hace cuando da voz a las posiciones partidarias del cumplimiento íntegro de las penas en un contexto de no debate ni referencia explícita a lo mismo.

En resumen, la práctica de manipulación informativa directa, evidente, no es tan habitual como en los temas estrictamente políticos. Sin embargo, hay algunos usos ilegítimos; algunas estrategias perniciosas en la eliminación de las cuales se debe seguir trabajando.

\subsection{Del cadáver al sujeto}

El sensacionalismo del que han hecho gala los informativos de televisión como instrumento de captación de audiencias continúa detrás de las representaciones mediáticas sobre violencia de género. Las imágenes juegan un papel fundamental en la tarea de exagerar y apelar al morbo.

En TVE continúan saliendo camillas transportando cadáveres al interior de furgonetas, zooms a las esposas de un detenido, planos de restos de sangre o planos detalle de los precintos policiales. Lo cierto es que la dictadura de las imágenes en televisión obliga a incluir imágenes de relleno que no siempre aportan información y muchas veces aportan morbo o dramatismo.

Antena 3 hace más uso de las imágenes espectaculares. En las noticias sobre explotación sexual se suceden planos americanos de trabajadoras sexuales, con ropa de trabajo - esto es, semidesnudas - que van des de media pierna hasta el cuello, planos de los escotes de las chicas y primeros planos de los culos. Esta reiteración de planos de carne al descubierto - con imágenes cedidas por la Dirección General de Policía - nos hace preguntarnos por el interés de las mismas. La espectacularidad, sin embargo, se alcanza con el tándem texto/imagen. En la noticia de la apertura del juicio contra el Brujo, la inserción del video del acusado en el plató de televisión se complementa con las descripciones intensas del personaje.

TV3 también usa en alguna ocasión las imágenes de cadáveres envueltos en sábanas e introduciéndolos en furgonetas, al igual que Canal9, que usa los cadáveres como imagen de relleno.

En la muestra analizada encontramos un uso bastante comedido de las imágenes morbosas y espectaculares en comparación con la gran cantidad de representaciones de la vida cotidiana en donde los actores viven y conviven, actúan y toman partido. Éste es el sujeto parlante al que nos referimos: los hombres y mujeres que participan en el cambio social, que se organizan y construyen un sujeto liberador. El paso de la representación mayoritaria de los sujetos en forma de cadáveres a la representación de los mismos en forma de sujetos que se manifiestan, trabajan y luchan por la erradicación de la violencia contra las mujeres es un elemento simbólico de gran relevancia. 


\section{Conclusiones}

El análisis de los discursos muestra cómo se ha conseguido identificar en las representaciones colectivas la violencia de género con la violencia de pareja. El zoom ejercido sobre esta parte del todo supone excluir o subrepresentar los aspectos estructurales de la violencia. Esta es una tendencia en las cuatro cadenas estudiadas que, sin duda, se relaciona con la imposición de un único marco de interpretación por lo que respecta al ámbito social. Las implicaciones del constreñimiento pasan por disminuir el control en los casos que no se ajustan a la interpretación dominante. Así pues, hemos visto como Antena 3 realiza un tratamiento más espectacular, sensacionalista y comercial en las noticias sobre prostitución y agresiones sexuales ${ }^{11}$.

En otro nivel de análisis, la distribución de modelos de mujeres representados en la muestra redunda en la imagen de las mujeres como víctimas, con su consecuente esencialización, o las mujeres que hemos denominado institucionales. Estas, el modelo A, no viven violencia, ostentan posiciones de éxito social (profesionales y políticas en su mayoría), y están integradas en la lógica patriarcal. Ellas representan la "normalidad social" alejada del conflicto. Porque la comprensión de la violencia como hecho social conlleva un doble proceso: de distanciamiento y de identificación. El modelo institucional permanece comprometido pero profundamente distanciado de las encarnaciones de la violencia.

Del análisis de los modelos de mujer y hombre representados se destila la necesidad de diversificar y pluralizar el abanico de identidades de género. Se constata que cuando se hace uso de una identidad estable y permanente, la otra parte de la relación recibe también una identidad inmutable. El tándem lo construye el modelo de mujer D, la víctima, con el modelo de hombre $\mathrm{C}$, el agresor. Cuanto más se centren los discursos en estos modelos, más se imposibilita la construcción de un sujeto femenino transformador de la realidad y más se cierra la identificación de los hombres como posibles maltratadores, no como sujetos con quienes avanzar en la igualdad. La falta de modelos alternativos o contramodelos de hombres supone una de las carencias más importantes en los medios.

Las cotas de sensacionalismo se reducen al tratarse de una muestra cargada de informaciones "en positivo" debido a la presencia del 25 de noviembre. Aunque el uso de frases dramáticas que condensan la intensidad del dolor de las familias de las víctimas continua presente, el uso de elementos espectaculares tanto en el texto como en las imágenes queda reducido a la mínima.

Por último, respecto al uso instrumental de las informaciones sobre violencia para otros fines, nos encontramos con la necesidad de estar atentos a prácticas que, no obstante, serán más proclives en las cadenas que más uso hagan de técnicas explícitas de manipulación. Y aunque en este artículo sólo aparecen los mensajes, desligados de su proceso de producción, merece la pena no despojar a los sujetos sociales concretos, los y las periodistas, de la capacidad de agencia para ofrecer discursos de resistencia dentro del campo.

${ }^{11}$ Lo mismo ha ocurrido con el caso Marta del Castillo que, al no estar tipificada como violencia de género, los medios han vulnerado todas las recomendaciones y protocolos. 
A partir de la visión de los resultados según cadena, nos encontramos que las diversas posiciones de los medios determinan el contenido estructural de sus discursos. Las posiciones se construyen a través de tres variables: la ideología política general que marcará la cercanía o el alejamiento respecto a las cuestiones feministas; el grado de noticiabilidad otorgado a la violencia como problema social —que se traduce también en la variedad de géneros informativos dispuestos - y el grado de control, reflexión y especialización existente en las redacciones. Desde los casos de minimización, como el de TV3, justificado por la recomendación del delegado del gobierno en materia de Violencia de Género y que une la postura proclive a las cuestiones feministas con altas cotas de control, pasamos a una TVE con un enfoque ambicioso y globalizador, también con un alto grado de control y proclividad para con la causa. En el otro extremo un enfoque minimizado, el de Canal9, con noticias muy breves, sin reportajes ni análisis, que se combina con un bajo grado de control y una ambivalencia en la corresponsabilidad con la violencia de género. Lo mismo le ocurre a Antena 3 con la diferencia de la maximización en la cobertura.

Con este trabajo se pretende aportar discusión sobre la actual representación de la violencia de género en la televisión, a la vez que se ofrecen algunas reflexiones para que los medios contribuyan, de hecho, en la erradicación de la violencia contra las mujeres, en la inclusión de modelos alternativos y contramodelos que se erijan como sujetos activos en la promoción de los buenos tratos.

\section{Bibliografía}

- Alberdi, Inés (2005): “Cómo reconocer y cómo erradicar la violencia contra las mujeres”. En Alberdi, Inés y Rojas, Marco (2005): Violencia: Tolerancia cero. Barcelona: Fundació La Caixa.

- Alberdi, Inés y Matas, Natalia (2002): La violència domèstica. Informe sobre els maltractaments a dones a Espanya. Barcelona: Fundació La Caixa.

- Alsius, Salvador (2009): "Lo que dicen los códigos deontológicos del Periodismo acerca del tratamiento informativo de la violencia contra las mujeres", [en línea] Disponible en: http://cimmco.bsocial.gva.es/textos/pdf_ponencias/salvador_alsius.pdf [20/01/2012].

- Ariznabarreta, Larritz et al. (2006): Tratamiento de la violencia de género en la prensa vasca. San Sebastián: Universidad de Deusto.

- Bosch, Esperanza y Ferrer, Victoria (2002): La voz de las invisibles. Las víctimas de un mal amor que mata. Madrid: Cátedra.

- Bosch, Esperanza; Ferrer, Victoria y Alzamora, Aina (2006): El laberinto patriarcal: reflexiones teórico-prácticas sobre la violencia contra las mujeres. Barcelona: Anthropos.

- Bourdieu, Pierre (1985): ¿Qué significa hablar?: economía de los intercambios lingüísticos. Torrejón de Ardoz: Akal. . (1997): Sobre la televisión. Barcelona: Anagrama.

- Bustelo, María; López, Silvia y Platero, Raquel (2007): "La representación de la violencia contra las mujeres como un asunto de género y un problema público en España”. En Bustelo, María y Lombardo, Emanuela (eds.) (2007): Políticas de igualdad en España y en Europa. Madrid: 
Cátedra, pp: 67-96.

- CAC - Consell de l'Audiovisual de Catalunya (2008): El tractament de les informacions sobre violència domèstica en els teleinformatius d'àmbit català entre els mesos d'octubre $i$ desembre de 2007. Anàlisi del seguiment de les recomanacions del CAC sobre el tractament de la violència de gènere durant el mes de novembre de 2007. Barcelona: CAC.

. (2009): Informe sectorial trimestral. La presència de les dones en la informació. Octubredesembre de 2008. Barcelona: CAC.

- Carballido, Paula (2009): "Medios de comunicación social y violencia de género. Una revisión desde la teoría del framing”. En Bernardo, José María et al: Retos de la comunicación ante la Violencia de género. Valencia: Tirant Lo Blanch.

- Conde, Fernando (2009): Análisis sociológico del sistema de discursos. Madrid: CIS.

- Fagoaga, Concha (1999): La violencia en los medios de comunicación. Maltrato en la pareja y agresión asexuada. Madrid: Dirección General de la Mujer de la Comunidad de Madrid.

- Fernández, Natalia (2003): La violencia sexual y su representación en la prensa. Rubí: Anthropos.

- Gallego, Joana (dir.) (2002): La prensa por dentro. Producción informativa y transmisión de estereotipos de género. Barcelona: Los libros de la frontera.

- García, Fernando J. y Casado, Elena (2010): Violencia en la pareja: género y vínculo. Madrid: Talasa.

- IORTV e Instituto de la Mujer (2006): Representación de la violencia de género en los informativos de TVE. Madrid: Instituto Oficial de la Radio y la Televisión.

- Kitzinger, Jenny (1999): “A sociology of media power: key issues in audience reception research”. En Greg Philo (ed.): Message received: Glasgow Media Group research, 1993-1998. Edimburg: Pearson, pp. 3-20.

- León Mejía, Ana (2009): “¿Disidencia dentro del feminismo?”. En RIS, Vol. 67, n³, pp. 559-588.

- López Díaz, Pilar (Coord.) (2007): Protocolo de actuación periodística y publicitaria sobre la igualdad de oportunidades entre hombres y mujeres y tratamiento informativo de la violencia de género. Vicepresidencia Dirección General de la Mujer.

- Lorente Acosta, Miguel (2001): Mi marido me pega lo normal. Barcelona: Crítica.

- Marugán, Begoña y Vega, Cristina (2002): "El cuerpo contra-puesto. Discurso feminista sobre la violencia contra las mujeres". En Bernárdez, Asunción (2001): Violencia de género y sociedad. Una cuestión de poder. Madrid: Ayuntamiento de Madrid, pp. 109-136.

- Ministerio de Sanidad, Política Social e Igualdad (2011): Encuesta sobre percepción social de la violencia de género. Madrid: Ministerios de Sanidad, Política Social e Igualdad.

- Osborne, Raquel (2009): Apuntes sobre violencia de género. Barcelona: Bellaterra.

- Van Dijk, Teun A. (1997): Racismo y análisis crítico de los medios. Barcelona: Paidós.

- Varela, Núria (2002): Íbamos a ser reinas: mentiras y complicidades que sustentan la violencia contra las mujeres. Barcelona: Ediciones B.

(2003): "Medios de comunicación y violencia de género: un mundo fuera de foco". En Medios de Comunicación y violencia contra las mujeres. Sevilla: Instituto Andaluz de la Mujer y Fundación Audiovisual de Andalucía.

- Vives Cases, Carmen (2005): La violencia contra la mujer en el espacio discursivo público. Madrid: Centro Reina Sofía para el Estudio de la Violencia.

- Witting, Monique (2006): El pensamiento heterosexual y otros ensayos. Barcelona: Egales.

- Xambó, Rafael (2010): "Medios de comunicación: de la comunicación de masas a la sociedad e la información". En Manuel García Ferrando (coord.) (2010): Pensar nuestra sociedad globalizada. Valencia: Tirant Lo Blanch. 